\title{
Urgences
}

\section{Programme du colloque}

Numéro 17-18, octobre 1987

L'esprit des lieux

URI : https://id.erudit.org/iderudit/025414ar

DOI : https://doi.org/10.7202/025414ar

Aller au sommaire du numéro

Éditeur(s)

Urgences

ISSN

0226-9554 (imprimé)

1927-3924 (numérique)

Découvrir la revue

Citer ce document

(1987). Programme du colloque. Urgences, (17-18), 7-7.

https://doi.org/10.7202/025414ar

Ce document est protégé par la loi sur le droit d'auteur. L'utilisation des services d'Érudit (y compris la reproduction) est assujettie à sa politique d'utilisation que vous pouvez consulter en ligne.

https://apropos.erudit.org/fr/usagers/politique-dutilisation/
Cet article est diffusé et préservé par Érudit.

Érudit est un consortium interuniversitaire sans but lucratif composé de l'Université de Montréal, l'Université Laval et l'Université du Québec à Montréal. Il a pour mission la promotion et la valorisation de la recherche. https://www.erudit.org/fr/ 


\section{PROGRAMME DU COLLOQUE}

\section{LUNDI 1 er JUIN:}

9h:

Accueil et inscription

17h30:

Cocktail de bienvenue

19h30:

Souper d'inauguration

\section{MARDI 2 JUIN}

9h:

Atelier mobile: visite de sites extérieurs de la région

14h:

Premier atelier:

présentation et animation: Louise Déry

Conférenciers: Frédéric-Jacques Temple, René Derouin, Luc Bureau, Domingo Cisneros

19h30:

Deuxième atelier:

Présentation et animation: Pierre Thibodeau

Conférenciers: Claude Mettra, Paul Chanel Malenfant, Daniel Buren*, Raymond Montpetit.

\section{MERCREDI 3 JUIN}

9h:

Troisième atelier:

Présentation et animation: Pierre Bruneau

Conférenciers: Paul-André Bourque, Paul Faucher, Helen Escobedo, Christian Morrissonneau.

13h30:

Quatrième atelier:

Présentation et animation: Guy Massicotte

Conférenciers: Jacques Pelletier, Robert Richard, Bill Vazan,

Pierre Laplante

17h30:

Clôture du colloque

Vernissage de l'exposition, au Musée régional de Rimouski

L'exposition L'Esprit des Lieux, présentée du 3 juin au 7 septembre 1987, réunissait des oeuvres de René Derouin, Helen Escobedo, Lise Labrie et Reno Salvail. Un catalogue de l'exposition est disponible, sur demande, au Musée régional de Rimouski.

* M. Daniel Buren n'a malheureusement pas pu participer au colloque; sa conférence était toutefois inscrite au programme que nous reproduisons ici fidèlement. 